\title{
Temporary Intraabdominal Cryptorchidism in the Weanling Rat Leads to Irreversible Azoospermia
}

\author{
Will J. Kort, Ph.D., ${ }^{*}$ Ineke Hekking-Weijma, B.Sc., ${ }^{*}$ and Marcei. Vermfid, B.Sc. $\dagger$ \\ ${ }^{*}$ Laboratory for Experimental Surgery and $\nmid$ Department of Pathology, Erasmus University, Medical Faculty, Rotterdam, The Netherlands
}

Submitted for publication July 13, 1990

To study surgical reversibility of intraabdominal cryptorchidism, a study in which weanling rats were made artificially cryptorchid was undertaken. At the same time both sperm ducts were anastomosed into the urine bladder (vasocystostomy) to enable sperm output measurements, which were performed by putting the animals in metabolic cages for $24 \mathrm{hr}$. Group I animals were reoperated on 2 weeks after the initial cryptorchidism operation to reverse this intervention by an orchiopexy operation; in Group II orchiopexy was carried out after 4 weeks, in Group III after 8 weeks. In Group IV, a control group in which only the vasocystostomy operation was performed, the rats were sham operated. The animals were followed for 3 months after orchiopexy. All control animals showed sperm output between 20 and 30 million of spermatozoa per $24 \mathrm{hr}$ from the age of 13 weeks on. However, experimental animals that had been de facto cryptorchid did not show any sperm output. Three out of 4 animals in which spontaneous descent of one or both testes had taken place showed sperm output from 6 to 8 weeks after orchiopexy. The results show that, notwithstanding the short periods of cryptorchidism, certain irreversible changes had already developed. (c) 1991 Academic Press, Inc.

\section{INTRODUCTION}

The incidence of failure of testicular descent in the full-term neonate amounts to $3 \%$, while the incidence in preterm infants reaches values of $30 \%$ or higher $[1,2]$. Those testes that will spontaneously descend postnatally will do so during the first year of life and by the age of 1 year the incidence of cryptorchidism approximates $1 \%$ [3]. The few publications that deal with the followup of these children show that untreated bilateral cryptorchidism will eventually lead to infertility $[4,5]$.

Treatment of cryptorchidism is performed either hormonally [6, 7], or surgically by orchiopexy [7-9], but generally not before 4 years of age. So far, the question of whether early treatment has a favorable effect on subsequent fertility has not yet been answered convincingly
[10]; nevertheless, the pros for treatment before the age of 2 years seem to be stronger than the cons [11].

To tackle the problem as to when to correct cryptorchidism, two experimental approaches are available, i.e., a clinical prospective trial, which takes at least 15 years, or an animal experiment, in which the clinical situation is mimicked. To our knowledge the first approach has not been undertaken so far. Also, experience with experimental animal models is very limited. The few animal studies on the subject carried out so far show that orchiopexy alters the negative influence of cryptorchid testicles on maturation $[12,13]$ but do not answer the question of what period of time or age of the animal is the borderline between reversible and irreversible damage leading to infertility.

As an attempt to contribute to the above-mentioned discussion, a study was undertaken in which, at 3 weeks of age (the age that the testicles will descend into the scrotum), rats were made artificially cryptorchid. The time span studied for cryptorchidism was 2,4 , and 8 weeks. To determine fertility, sperm output was measured by means of vasocystostomy [14].

\section{MATERIALS AND METHODS}

Experimental design. Twenty-five inbred 3-weekold Wag/Rij male rats weighing 45-55 g were randomly divided into four groups of animals. Animals in Groups I to III were made artificially cryptorchid by suturing both testicles to the abdominal wall. At the same time all animals (Groups I-IV) were vasocystostomized, i.e., both deferential ducts were united to the urine bladder. Two weeks after the first operation Group I animals were operated on again to reverse the cryptorchidism by an orchiopexy operation (Orchi). Four weeks after the first operation, cryptorchidism was corrected in Group II animals, while Group IV rats were sham operated. Finally, 8 weeks after cryptorchidism Group III rats underwent the orchiopexy operation.

Apart from the week when they were operated on, all animals were placed in metabolic cages once a week to collect urine. The experiment was terminated when the animals were followed for 3 months after orchiopexy. At 
that time the animals were sacrificed and testicles and epididymis were taken for histopathological analysis.

Animals and husbandry. Wag/Rij rats were obtained from Harlan-CPB, Zeist, The Netherlands. The animals were individually housed in Makrolon cages on presterilized wood chips and received a commercial rat chow (Hope Farms AM II, Woerden, The Netherlands) and acidified tap water ( $\mathrm{pH}$ 3.0) ad libitum. The animal room was air conditioned and controlled with a $12 \mathrm{~h}$ light/12 h dark cycle.

Vasocystostomy. The operation technique which has been previously described by us for the adult rat $[14,15]$ was slightly modified for the weanling rats used in the present experiment. After anesthesia with ether was induced, the abdominal area of the animals was shaved using clippers. A small incision was made just above the pubis. At both sides the ductus deferens was transsected close to the seminal vesicles. In the bladder two small lateral incisions were made through which both ductili deferens were pulled. The other ends of the ductus deferens were ligated. The ductili deferens were fixed in the bladder with 8-0 Ethilon sutures using a BV-2 needle (Ethicon, Norderstedt, FRG). The bladder wall was closed with the same suture material. The abdominal wound was closed with 5-0 Miralene sutures using a HRT-17 needle (B. Braun Melsungen, FRG). Operations were carried out using microsurgical techniques and were performed using an operation microscope under clean but nonsterile conditions.

Artificial cryptorchidism. Testicles of 3-week-old $\mathrm{Wag} / \mathrm{Rij}$ rats had in most cases not yet descended into the scrotum and could be found low in the inguinal canals. They could easily be retracted into the abdominal cavity where the testicular tunica was fixed loosely with a 5-0 Miralene suture to the abdominal wall below the left and right kidney. Operations were carried out in the same operative session as the vasocystostomy operation. The sham operations in Group IV consisted of placing a loose ligature through the testicular tunica and putting the testicles back into the scrotum.

Orchiopexy operation. The testicles were carefully dissected from the abdominal wall and the ligature connecting it was cut. The testicles were then gently pulled into the scrotal sac and fixed there with a Miralene 5-0 suture connecting the testicular tunica and the scrotal muscles.

Sperm output measurements. Once a week all animals were put into metabolic cages. In the week that the animals were operated on they were not measured as the metabolic cages were considered too stressful under the circumstances. In the metabolic cages the animals received their normal food regimen of rat chow and water ad libitum. After exactly $24 \mathrm{hr}$ urine volume was measured and a sample into which the number of spermatozoa was counted was taken using a counting chamber and counting 25 squares. Sperm output measurements were given as the total number of spermatozoa produced per $24 \mathrm{hr}$ (i.e., number of spermatozoa $/ \mathrm{ml} \times$ volume/24 hr).

Macroscopical and microscopical evaluation. At orchiopexy operation and termination, macroscopical aspects of the testicles were assessed for size (measured by calipers), granulomas, bladder stones, and other pathological changes. Furthermore, at termination the animals were necropsied and the testicles and epididymis were put in Bouin's fixative for histopathological evaluation. For this, $5-\mu \mathrm{m}$ paraffin sections were stained with HAS (hematoxylin, azophloxin, saffron) and PAS (periodic acid Schiff).

Statistics. For determination of statistically significant differences in the histomorphological data the parameter-free test of Yates [16] was chosen. A difference was considered statistically significant when $P<0.05$.

\section{RESULTS}

Survival. From the 25 animals originally operated on only one rat (Group IV) did not survive the planned observation period and was considered a technical failure and was not further evaluated in the results. This particular animal died 2 weeks after vasocystostomy for no obvious reasons.

Macroscopical evaluation. When the orchiopexy operation was carried out, $7 / 19$ rats showed that one or both of the testes had attempted to reach the scrotum, and $7 / 38$ testicles were found low in the inguinal canal, whereas $5 / 38$ had descended completely into the scrotal sac (Table 1). In these animals the testes were found with a loop of the ligature at the top and completely loosened from the abdominal wall. Apparently, in these cases the abdominal tissue through which the suture was placed was not strong enough to withhold the testes from descent.

Furthermore, in Table I, the macroscopically visible alterations in growth of the testicles are shown. Eight of 38 testicles showed a marked growth retardation, which was equally divided in the three experimental groups.

Bladder stones were a common finding, as 6/24 animals showed small or large stones at termination (Table 1). In earlier studies in the rat using the method of vasocystostomy, the incidence and frequency was the same [14]. The bladder stones, most of which were smooth and grey-white in color, could reach a size of $10 \mathrm{~mm}$ or more. However, signs of discomfort in animals with bladder stones were not seen, and urine production was not impeded.

At termination the macroscopy of the testicles showed an increase in the number of pathological changes in all experimental groups. Atrophy was assessed in 16/38 testicles, a doubling of the number seen at orchiopexy, despite the fact that the testicles were put back in the scrotum.

Sperm output measurements. The 5 animals of Group IV that were not cryptorchid first showed sperm in the urine at the age of 6-8 weeks (one rat at 6 weeks, 3 at 7 weeks, and 1 at 8 weeks). At 13 weeks of age mean 
TABLE 1

Macroscopical Appearance of Testicles in Cryptorchid Rats

\begin{tabular}{|c|c|c|c|c|c|}
\hline \multirow{4}{*}{$\begin{array}{l}\text { Rat No./ } \\
\text { group }\end{array}$} & \multirow{2}{*}{\multicolumn{2}{|c|}{ Appearance at orchiopexy }} & \multicolumn{3}{|c|}{ Appearance at termination } \\
\hline & & & \multicolumn{2}{|c|}{ Macroscopy } & \multirow{3}{*}{$\begin{array}{c}\text { Sperm in } \\
\text { urine }^{\circ}\end{array}$} \\
\hline & Location $^{a}$ & Macroscopy ${ }^{b}$ & & & \\
\hline & $\mathrm{R} / \mathrm{L}$ & $\mathrm{R} / \mathrm{L}$ & $\mathbf{R} / \mathbf{L}$ & Stones & \\
\hline $21 / \mathrm{I}$ & $-1-$ & $-/ \mathrm{A}$ & $-/ \mathrm{A}$ & - & - \\
\hline $22 / \mathrm{I}$ & $-1-$ & $-1-$ & $-1-$ & - & - \\
\hline $27 / \mathrm{I}$ & $-1-$ & $-1-$ & $-1-$ & + & - \\
\hline $28 / \mathrm{I}$ & $-1-$ & $-1-$ & $\mathrm{A} / \mathrm{A}$ & - & - \\
\hline $32 / \mathrm{I}$ & I/I & $\mathrm{A} / \mathrm{A}$ & $\mathrm{A} / \mathrm{A}$ & - & - \\
\hline $36 / \mathrm{I}$ & $\mathrm{I} / \mathrm{I}$ & $-1-$ & $-1-$ & + & - \\
\hline $23 / \mathrm{II}$ & $\mathrm{I} / \mathrm{S}$ & $\mathrm{A} /-$ & $\mathrm{A} /-$ & + & $t^{d}$ \\
\hline $24 / \mathrm{II}$ & $\mathrm{I} / \mathrm{I}$ & $\mathrm{A} /-$ & $\mathrm{A} / \mathrm{N}$ & - & - \\
\hline $26 / \mathrm{II}$ & $-1-$ & $-1-$ & $-/ \mathrm{A}$ & - & - \\
\hline $29 / \mathrm{II}$ & $-1-$ & $-1-$ & $-1-$ & + & - \\
\hline $35 / \mathrm{II}$ & $\mathbf{s} /-$ & $-1-$ & $-1-$ & - & $t^{e}$ \\
\hline $37 / \mathrm{II}$ & $-1-$ & $-1-$ & $-1-$ & - & - \\
\hline $41 / \mathrm{II}$ & $-1-$ & $-1-$ & $-1-$ & - & - \\
\hline $25 /$ III & / & -1 & -1 & & \\
\hline $31 / \mathrm{III}$ & $\mathrm{s} / \mathrm{s}$ & $-1-$ & $-1-$ & - & $+f$ \\
\hline $34 / \mathrm{III}$ & $\mathrm{S} /-$ & $-1-$ & A/A & - & - \\
\hline 38/III & $-1-$ & $\mathrm{A} / \mathrm{A}$ & $\mathrm{A} / \mathrm{A}$ & + & - \\
\hline 40/III & $-1-$ & $-1-$ & $\mathrm{A} / \mathrm{A}$ & - & - \\
\hline $42 / \mathrm{III}$ & $-1-$ & $-/ \mathrm{A}$ & $\mathrm{A} / \mathrm{A}$ & - & - \\
\hline $30 / \mathrm{IV}$ & & & $-1-$ & + & +++ \\
\hline $33 / \mathrm{IV}$ & & & $-/ \mathrm{N}$ & - & +++ \\
\hline $39 / \mathrm{IV}$ & & & $-1-$ & - & +++ \\
\hline $43 / \mathrm{IV}$ & & & $-1-$ & - & +++ \\
\hline $45 / \mathrm{IV}$ & & & $-1-$ & - & +++ \\
\hline
\end{tabular}

${ }^{a} \mathrm{I}$, inguinal site; $\mathrm{S}$, scrotal site.

${ }^{b} \mathrm{~N}$, area(s) of necrosis or granuloma(s); A, atrophia, testis has decreased $>20 \%$ in size.

${ }^{c}$ Sperm in urine, $+=1-5 \times 10^{6} / 24 \mathrm{hr} ;++=6-20 \times 10^{6} / 24 \mathrm{hr} ;+++$ $=>20 \times 10^{6} / 24 \mathrm{hr}$.

${ }^{d}$ First sperm appearing 6 weeks after orchiopexy.

First sperm appearing 8 weeks after orchiopexy.

${ }^{f}$ First sperm appearing 7 weeks after orchiopexy.

values reached $20 \times 10^{6}$ or more, whereafter sperm output remained at levels between 20 and $30 \times 10^{6}$ (Fig. 1 ).

Only 3 out of 19 rats in the groups of experimentally induced cryptorchidism showed sperm in the urine, 2 in Group II, and 1 in Group III. However, these 3 rats at orchiopexy had established that one or both of the testicles had descended spontaneously into the scrotum. All other rats, including one more rat with a testicle in the scrotal sac, and a number of rats in which testicles were found low in the inguinal canal, did not show any sperm output throughout the complete observation time of 12 weeks after orchiopexy.

Histopathological evaluation. The results of the histopathological evaluation are shown in Table 2. The histology of the testicles showed two complete necrotic testicles. One of these rats was a sham operated control (vasocystostomized) rat. It seems logical to suppose that impeded blood supply due to the operative procedures was the cause of this.
Interstitial oedema is seen through all experimental groups, although the severity of this is increasing according to the time the testicles were placed ectopically. Interstitial fibrosis with a slight increase in the number of macrophages, lymphocytes, and interstitial cell hyperplasia was observed as more or less the same in all experimental groups; in the control group this was not present. Signs of seminiferous tubular regressive changes, such as atrophy of the germinal epithelium, in the end-stage swollen tubular basement membranes with a few Sertoli cells on it, were seen in almost all testicles, with no statistically significant differences among the experimental groups. Spermatogenesis was present at a level far below normal (5-70\% of the tubules showing spermatogenesis) in most of the testicles involved, with almost normal appearances in the testicles of the animals in Group IV. No correlation was seen between the score of spermatogenesis and sperm output. For instance, Rats 29 and 35 were both in the same group and had the same score for spermatogenesis and sperm in the epididymis, but only rat 35 had some sperm output. On the other hand rat 31 had a score of ++ for spermatogenesis in both testicles and still had detectable sperm output.

Morphological investigation showed that mature spermatozoa were present in all testicles and epididymal ductules of the rats from the control group. High scores of +++ were found in 5 more rats, 3 of which had detectable sperm output. Finally, one of the remaining 2 rats had both testicles descended into the inguinal canal as was established at orchiopexy.

\section{DISCUSSION}

Clinical trials on the follow-up of cryptorchid patients after orchiopexy encounter a number of problems. To

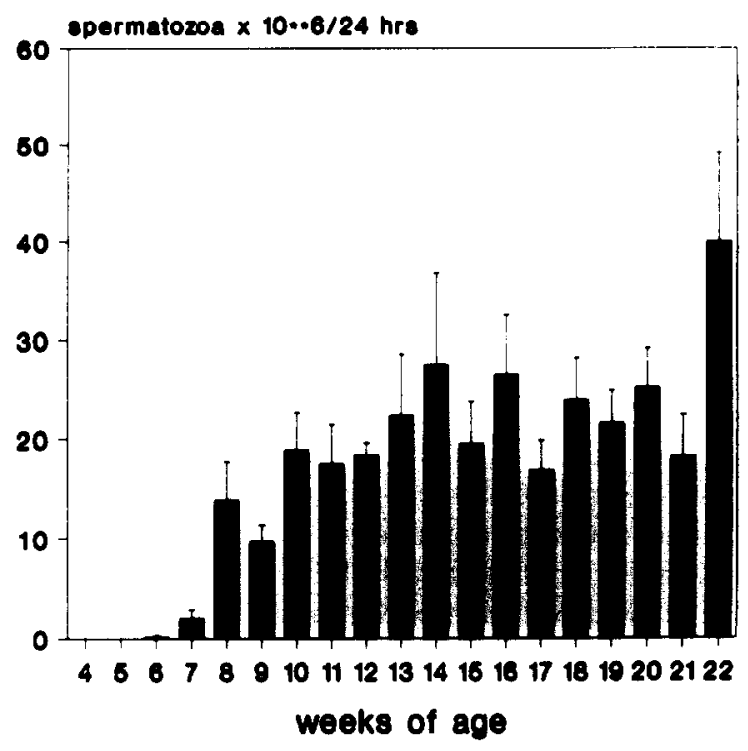

FIG. 1. Output of spermatozoa per $24 \mathrm{hr}$ in urine of vasocystostomized rats from Group IV (sham operated, noncryptorchid). 
TABLE 2

\section{Pathology Showing in Testicles and Epididymis of Cryptorchid Rats}

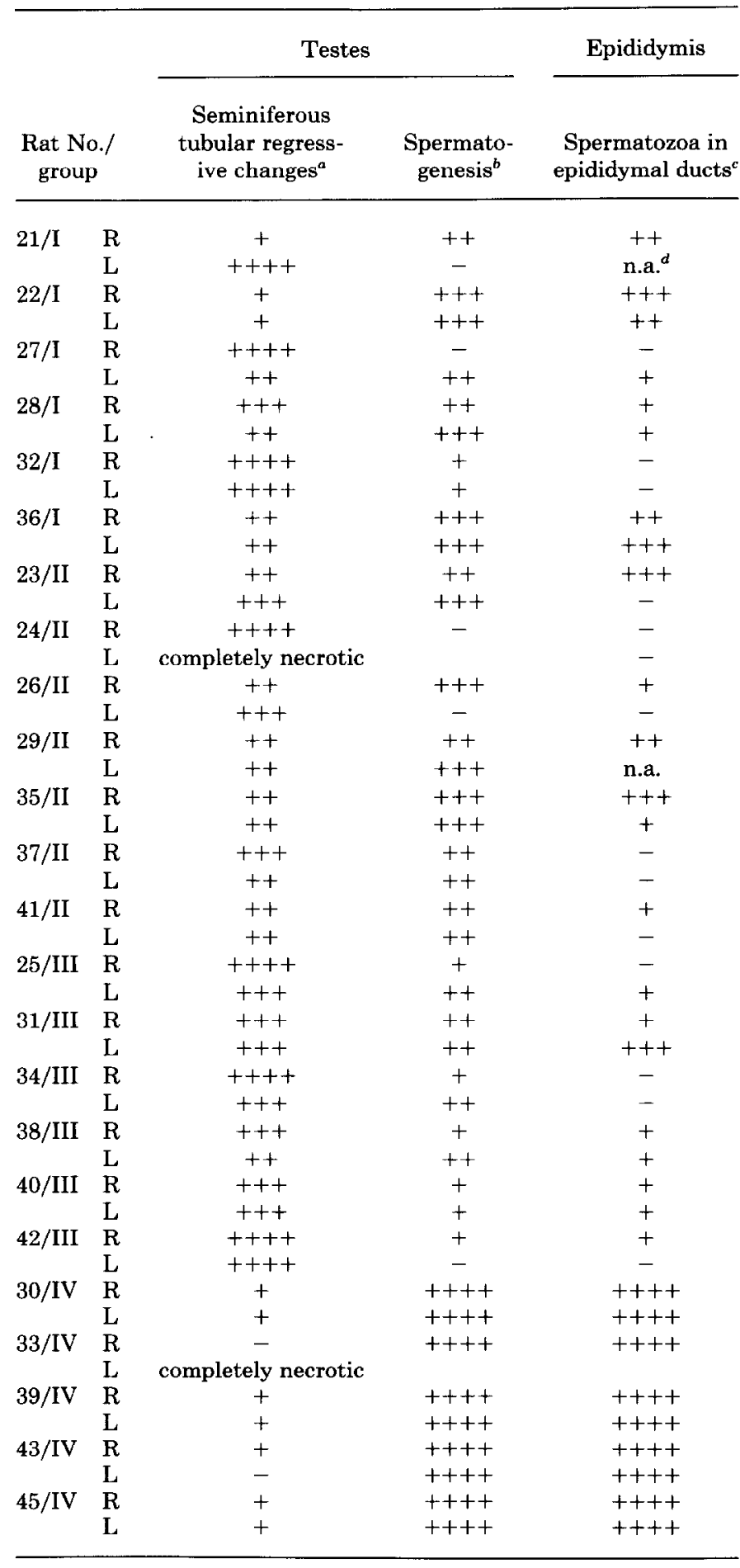

\footnotetext{
${ }^{a}$ Seminiferous tubular regressive changes:,,,,-++++++++++ (all tubules normal; $1-10 \%$ of the tubules with regressive changes, $11-50 \%, 51-90 \%, 91-100 \%$ )

${ }^{b}$ Spermatogenesis:,,,,-++++++++++ (no tubules showing spermatogenesis; $1-10 \%$ of the tubules showing, $11-50 \%$; 91-100\%).

' Spermatozoa content epididymal ducts:,,,,-++++++++++ (all tubules empty; $1-10 \%$ of the tubular lumen filled with spermatozoa; 11-50\%; 51-90\%; 91-100\%, respectively).

${ }^{d}$ N.a., not available.
}

name only a few: the lengthy follow-up time, the difficulty to assess the location of the testicles even for an experienced pediatrist, and the many differences in treatment schedules. For these reasons such data are very much limited and it is hard to make conclusions from them. Part of the discussion concerning the "why, how, when" related to the treatment of cryptorchidism is because of the above-mentioned facts [11]. Another approach is to carry out studies in experimental models where clinical situations can be mimicked. A few such models were presented [17-19]. Most studies were carried out in rats although bulls and pigs were used as well. Because microsurgical techniques are adopted in many experimental surgical laboratories now, it is no longer necessary to use larger animals simply for reasons of the surgical technical inability to work on small animals. When the rat is the animal of choice the advantages of the availability of comprehensive data on all kinds of aspects of cryptorchidism gathered in this animal species will be obvious.

In the present study the animals were made cryptorchid at the age of 3 weeks. This was done not only because of surgical technical reasons, but also because normally the testes have not yet descended into the scrotum, implying that operations on an earlier age would not have given another picture of testicular development. Uniformly the procedure of artificial cryptorchidism was by means of obliteration of the inguinal canal. In the present study another approach was chosen because of the temporary nature of the intervention. In most cases the ligature connecting the testis to the abdominal wall proved to be sufficient in keeping the testis in the abdominal area. However, we have to admit that the procedure might as well have led to twisting of the testicular vasculature, resulting in kinking of the vessels leading to necrosis, as was observed in the study.

Parameters of fertility in animal studies on cryptorchidism were sperm counts or the ability of the males to impregnate females $[12,20]$. The latter, although being the most essential expression of fertility, is a "yes/no" parameter at a certain time point and as such does not show any gradualism in quantity or time.

To establish sperm output in fact, two ways are present, i.e., to harvest ejaculate, for instance by electroejaculation [21], or by a vasocystostomy. The first-mentioned methods give an instant picture of sperm production but it is not possible to get more than an idea of sperm production over a certain time period. Therefore in the present study the method of vasocystostomy was chosen enabling sperm output measurements by placing the animals in metabolic cages. The procedure is minimally stressful and as such is a much less ruthless method compared to electroejaculation. As been described earlier the method is of no hindrance to the animal, and in the species studied, the animals could endure the procedure for long periods of time [14, 15, 22]. Also in the present study in the sham operated control group the animals that were vasocystostomized had constant 
sperm outputs after maturity of values between 20 and 30 million per $24 \mathrm{hr}$ which are values comparable to those given in the literature $[14,15]$.

The results of the present study show that all animals that were made cryptorchid even for a period of only 2 weeks had no appearance at all of spermatozoa in the 12 weeks' observation time after orchiopexy. This occurred despite the fact that the actual growth of the testicles did not seem to be hampered, as could be shown by macroscopy and microscopy at termination of the animals in all experimental groups.

These results are in accordance to suggestions made in the literature where it has been postulated that the prognosis of testicular function after orchiopexy of the partially or completely retracted cryptorchid testes is very poor and actually never seems to contribute to fertility $[8,23-26]$.

The macroscopical and the microscopical appearance of the testicles at termination more or less gives an explanation for the lack of sperm output observed. Testes and epididymis in all cryptorchid rats were very much damaged although in a number of cases signs of spermatogenesis were still present. But this latter did not seem to contribute to any sperm output at all.

Our conclusion based on the results of the present study is that even a very short period of time of cryptorchidism is enough to impede fertility completely. Carefully translating this to the clinical situation might indicate that the present policy of urologists or pediatric surgeons not to perform an orchiopexy before the age of 2 years [11] could well be too late for the boy in question for his eventual testicular function; particularly in double-sided cryptorchids, this would be of important consequence.

\section{REFERENCES}

1. Villumsen, A. L., and Zachau-Cristiansen, B. Spontaneous alterations in position of the testis. Arch. Dis. Child. 41: 198, 1966.

2. Scorer, C. G., and Farrington, G. H. Congenital Deformities of the Testes and Epididymis. London: Butterworths, 1971.

3. Jackson, M. B., and the John Radcliffe Hospital Cryptorchidism Research Group. The epidemiology of cryptorchidism. Horm. Res. 30: 153, 1988.

4. Kogan, S. J. Fertility in cryptorchidism. An overview in 1987. Eur. J. Pediatr. 146(S): S21, 1987.

5. Cendron, M., Keating, M. A., Huff, D. S., Koop, C. E., Snyder, H. Mc. C., III, and Duckett, J. W. Cryptorchidism, orchiopexy and infertility: A critical long term retrospective analysis. $J$. Urol. 142: 559, 1989.

6. de Muinck Keizer-Schrama, S. M., Hazebroek, F. W., Drop, S. L., and Visser, H. K. LH-RH nasal spray treatment for cryptorchidism. A double-blind, placebo-controlled study. Eur. J. Pediatr. 146(S): S35, 1987.

7. Raifer, J. Surgical and hormonal therapy for cryptorchidism: An overview. Horm. Res. 30: 139, 1988.
8. Hadziselimovic, F., Herzog, B., Höcht, B., Hecker, E., and Buser, M. Screening for cryptorchid boys risking sterility and results of long-term buserelin treatment after successful orchiopexy. Eur. J. Pediatr. 146(S): S59, 1987.

9. Mengel, W., and Hecker, W. Cryptorchidism-Surgical treatment and its date. Pediatr. Adolesc. Endocrinol. 6: 160, 1979.

10. Thorup, J., Kvist, N., Larsen, P., Tystrup, I., and Mauritzen, K. Clinical results of early and late operative correction of undescended testes. Br. J. Urol. 56: 322, 1984.

11. de Muinck Keizer-Schrama, S. M., and Hazebroek, F. W. The Treatment of Cryptorchidism. Why, How, When, Clinical Studies in Prepuberal Boys. Doctoral thesis Erasmus University. Rotterdam, 1986.

12. Kogan, B. A., Gupta, R., and Juenemann, K.-P. Fertility in cryptorchidism: Further development of an experimental model. $J$. Urol. 137: 128, 1987.

13. Kogan, B. A., Gupta, R., and Juenemann, K.-P. Fertility in cryptorchidism: Improved timing of fixation and treatment in an experimental model. J. Urol. 138: 1046, 1987.

14. Kort, W. J., Westbroek, D. L., tenCate, R., vanAndel, M. V., Vreeburg, J. T., and MacDicken, I. Vasocystostomy, a new technique of sperm output measurement. Eur. Surg. Res. 7: 297, 1975.

15. Vreeburg, J. T., vanAndel, M. V., Kort, W. J., and Westbroek, D. L. The effect of hemicastration on daily sperm output in the rat as measured by a new method. J. Reprod. Fertil. 41: 355, 1974.

16. Yates, F. The analysis of contingency tables with groupings based on quantitative characters. Biometrika 35: 176, 1948.

17. Juenemann, K.-P., Kogan, B. A., and Abozeid, M. H. Fertility in cryptorchidism: An experimental model. J. Urol. 136: 214, 1986.

18. Demura, R., Suzuki, T., Nakamura, S., Komatsu, H., Jikibi, K., Odagiri, E., Demura, H., and Shizume, K. Effect of uni- and bilateral cryptorchidism on testicular inhibin and testosterone secretion in rats. Endocrinol. Jpn. 34: 911, 1987.

19. Dijkstra, G., Fentener vanVlissingen, J. M., Wensing, C. J., vanDorst-Bruijns, P. M., Degenhardt, H. J., Erkens, J. H., and vandeWiel, D. F. Chronic GnRH administration in prepubertal male pigs. A model to evaluate the effects of GnRH treatment in cryptorchidism. Act. Endol. 118: 109, 1988.

20. Urry, R. L., and Middleton, R. G. Evidence for a contralateral effect of unilateral cryptorchidism on spermatogenesis, enzyme systems and sperm transport of the scrotal testicles. Surg. Forum 34: 649, 1983.

21. Lawson, R. L., Krise, G. M., and Sorensen, A. M., Jr. Electroejaculation and evaluation of semen from the albino rat. J. Appl. Physiol. 22: 174, 1967.

22. Hooker, R. H. Vasocystostomy in the rabbit: Surgical technique and sperm outflow. J. Androl. 3: 147, 1981.

23. Ludwig, G., and Potempa, J. Der optimale Zeitpunkt der Behandlung des Kryptorchismus. Dtsch. Med. Wochenschr. 100: $680,1973$.

24. Eldrup, J., and Steven, K. Influence of orchiopexy for cryptorchidism on subsequent fertility. Br. J. Surg. 67: 269, 1980.

25. Alpert, P. F., and Klein, R. S. Spermatogenesis in the unilateral cryptorchid testis after orchiopexy. J. Urol. 129: 301, 1983.

26. Mieusset, R., Bujan, L., Mansat, A., Pontonnier, F., and Grandjean, H. Hyperthermia and human spermatogenesis: Enhancement of the inhibitory effect obtained by "artificial cryptorchidism." Int. J. Androl. 10: 571, 1987. 